\title{
Research on Psychological Health Problems of the Contemporary College Students
}

\author{
Kai WANG ${ }^{a}$, Yanming CHENG ${ }^{\text {b, }}$ \\ College of Electrical \& Information Engineering, Beihua University, Jilin City, Jilin Province, China \\ a178971787@qq.com, bmychengniu@163.com
}

Keywords: College Students; Psychological Problems; Prevent and Solv

\begin{abstract}
The psychological health problems of the contemporary college students mainly represent loneliness and self-abasement, weak nerves, anxious depression, unstable emotion, lack of confidence, interpersonal relation disturbance and many other aspects. This paper analyzed the characteristics to the psychological health problems existed in current college students, put forward the reason for the problems as well as methods on how to prevent and solve. By means of setting up educational courses on psychological health in college, developing publicity campaigns on psychological health, enhancing the construction of teaching staff among psychological consultants and university counselors, and doing well in guiding work for job selection and career to assist college students overcome psychological problems.
\end{abstract}

\section{Introduction}

"The real health is the tendency for perfect status in aspects from physical, mental and social adaption." ---which is the health defined by WHO (World Health Organization. With the forward society and development economy, the value and mental characteristic in contemporary college students appeared numerous new changes, some of them cannot adjust mentality or adapt new changes in time so that psychological problems were caused and a series of extreme behaviors were resulted, which have taken severe influence to the learning, living, safety and stability works. The counselor is the vital part among the teaching staff and management team in institutions of high education; he is the confusion clarifying person, guider of special learning, navigator of life development, caring person in living and mental for college students, which makes the counselor an important role in the growth and talent to the students. Therefore it is particular significant to know the reasons for the students to be psychologically anxious and explore the relevant countermeasures, thus to reinforce psychological health education, optimizing mental quality, develop psychological consultation, prevent various abnormal mentality, improve the ideological and ethical standards, scientific and cultural quality, physical and psychological health quality[1-3].

\section{Common Characteristic in Psychological Problems of College Students}

The college students are in the medium term of youth, which is the most intense and obvious stage of psychological changes in their life. And it happens occasionally that unbalanced mental development, unstable emotion and psychological conflict. The common psychological problems mainly shown as follows:

Adjustment disorder:This is relatively common among the freshmen. After leaving their parents and teachers who are relied for a long time, some students find themselves conflict in independent and reliance facing by the new group, new living style and new study features, they feel lonely and self-abasement, low-energy and depressed emotion.

Neurasthenia:This is a kind of psychological illness with high prevalence rate among the college students. It ranks with high ratio for the reason of students quit school. And the key features are liable to excitement and quick tired, decentralized attention, memory deterioration, instable emotion, etc.

Interpersonal relation disturbance: On the one hand, the students would not like to open their hearts, and they close themselves; on the other hand, they are eager to obtain friendship through social 
contact, show their power. All of these will definitely generate conflicts to the students who have character flaws, and difficult to resolve.

Emotional disorder---problems of love and sex psychology: As entering into medium stage in youth, the college students are basically with mature sexual physiology. Their sex consciousness becomes heightened, and they are showing desire in deploring and attempting in sexual relations. However when they are unable to solve the "sex" confusion rationally and scientifically, psychological disorders such as annoyance, insomnia, anxiety, repression, and instable emotion will be resulted, and even worse, the insanity, words and deeds out of control, criminal phenomenon will be caused[4].

Conflict between ideal and reality:The value orientation to the college students come up with deep changes under complex environment. Some of them have not formed complete and stable outlook of life and value, they don't have a clear ideal goal, which make them represent contradictory mentality or varied status. By self-centeredness in dominant ideas and pursuing realization of self-worth, it results rising negative factors in contradictory orientation, aggravating passive mentality, losing faith, deviating recognition, chasing in a blind way, showing lose, indifferent and confused towards the expectations of ideal and reality.

Pressures taken from competitiveness in job hunting and selection:The difference from the aspects of employment concept, career opportunity and some others among the college student individual are becoming larger than before. Facing the fierce competition, some students show their psychological problems, for instance, lacking of confidence, having grandiose aims but puny abilities and fearing society.

\section{Reasons Caused Psychological Problems to College Students}

For the above commonly seen psychological problems to college students, the causes of which are mainly social factor, school factor, family factor and personal factor.

Competitive pressure in society:At present our country is in a transformation period from planned economy to market economy, with the intensifying competitiveness, especially the reform initiatives which involved with vital interests to college students have been implemented, the students are confronting with a more complex and varied social environment. This is a reason which caused considerable mental stress.

Campus environment: $A$. the changes to the environment and character will bring psychological inadaptation; B. the influence from educational process. Some colleges only highlight knowledge education, professional education, rather than ideology and morality education to students; $\mathrm{C}$. impact from interpersonal relationship. If the interpersonal relationship turns good, they will be happy and cheerful. However if one is in a tense relationship, he will be in bad mood and annoyed; D. impact from unhealthy school culture, for example, star-chasing, vogue chasing, falling for table-board and restaurant, being infatuated to internet, etc.

Family factor:A. Strict control, compelling orders, many criticizing and accusing by their parents, the children show timid, self-abased, sensitive and obsequious in the interpersonal relationship; B. The overprotection and spoiling from parents make the students highly dependency, cowered when meeting something, low self-control ability and self-confidence; C. Being treated in misconduct way, without constraining force by their parents, they behave as self-centeredness, they don't know how to respect others and difficult to adapt group living.

Personal factor: The undergraduates are now in a key stage that is mentality grow fast and moving forward maturity. What they cared about are self-development, designing ego model, emphasizing independence. They have their own opinions, pride, self-confidence, superiority complex and aspiration with high degree. Nevertheless, with their insufficient self-assessment ability, lacking of social experience, it is likely to generate contradictory between ideal and reality. Once they find themselves in reality are not the ones in ideal with their self-partiality attitude, uneasy and pain from bottom of heart will be felt. 


\section{Preventing and Solving Psychological Problems of College Students}

Master psychological knowledge, preventing mental illness:Setting up psychological courses, such as "college psychology", "society psychology", "cognitive psychology", "interpersonal relation psychology", "mental health of college students"; holding the lectures and movements; actively organizing the students to join in the psychological health publicity day, publicity week and publicity month; establishing three-level working mechanism over students, counselors and psychological counselors. The aim of the above measures is to enrich students' knowledge on psychology, let them recognize themselves correctly, strengthen their ability to adjust themselves, clear the direction and treat the conflicts in real life with a right way[5].

Strengthen the psychological guidance in colleges and universities; reinforce the construction of psychological consultants and counselors:Firstly, by the aim-targeted training, improve the psychological consultants' quality. Secondly, carrying out the screening work against psychological problems among students, establishing files, and making exchange with them periodically. Finally, develop publicity activities with more efforts, setting the psychological consultation mailbox, open hot-line, organize psychological test, launch exchange, hold lecture, and various other forms.

Attach importance to the construction of campus culture; create a favourable social environment for psychology:One of the most vital contents to cultivate health psychology for college students is to build a healthy campus environment with culture. This could be realized in terms of positively implementing teaching, scientific research, management, service, social practice and extra-curricular activities, for example, the reading seminar, lecture representation, debate, symposium, art festival, sports festival, science popularization festival, club, exhibition of painting and calligraphy, moot court, etc.

Doing well in guiding work for job selection and career:Relying on quality expansion, promoting students to keep mental health, this could be realized in terms of: establishing platforms simulate job fair to make the students enter into job market in advance and represent their specialties. The students will obtain confidence through these activities; enhance their ability to communicate with others. And in this way favourable metal state will be seen on them. Taking the opportunity from students' loans, scholarships and subsidies, to cultivate honesty and trustworthiness features. Taking work-study program as a carrier, with the aim of endow students with self-improving spirit. Opening up career guidance course, in this way creating a nice condition for the students to get a job and choosing a job will be realized. In the meantime adjusting course content according to market requirements, and the competitive capacity on the market by the students could be boosted. Through these aspects, students could face the market selection with positive mentality and healthy emotion.

Combination of psychological health education and ideological political education:These two educations belong to educate people, there are internally inevitable connections between them, but discrepancy existed. The former emphasizes on enhancing personal psychological health, while the latter focuses on cultivating students' world view, life view, value and moral outlook. Hence the emphasis of these two educations should be grasped, and combined closely together. Proceed with psychological view to remove the psychological disorder by applying rehabilitation approach.

The contemporary college students are staying in a transforming period from immature to mature, from indeterminate to setting. During this period all kinds of factors will make them easy to change thoughts and behaviors with some incorrect views, thus unhealthy emotions, and psychological problems would be generated, it will further impact them to set a right world view, life view and value. Consequently, the publicity and popularization of psychological health knowledge should be done, in order to get acquaintance of common problems and reasons on the problems. By treating the problems with a scientific attitude, students' confusion will be removed, and their ability on overcoming difficulty and frustration will be enhanced. Furthermore, through widely developing education and practical activity on the psychological healthy education of college students with Chinese characteristics and high effectiveness, students could get good self cognition, perfect personality to adapt social development on and on. 


\section{References}

[1] Cui Zhilin, Wang chao. Current Situation and Reflection towards Psychological Health of College Students [J]; Course Education Research. No.08, 2013.

[2] Huang wei. Research on Psychological Health Education of College Students under New Situation[J]; Scientific Public (Scientific Education). No.03, 2013.

[3] Li Xinming. Research on Psychological Problems Commonly Existed among College Students and Countermeasures [J]; Xiangtan University Social Sciences Journal; No.1, 2002.

[4] Yao Qiyuan. Current Situation and Countermeasures to Psychological Health of College Students [J]; Scientific and Technical Information. No.14, 2013.

[5] Zhang Yuanhong, Kong Qingna. Discussion on the Psychological Educational Course Reformation to College Students under New Situation [J]; Research on Ideological and Political Education. No.02, 2013. 